\title{
Using Flexible Criteria to Improve Manufacturing Validation During Product Development
}

\author{
Patrick C. Hammett, ${ }^{1}$ Shannon M. Wahl and Jay S. Baron \\ University of Michigan, 2901 Baxter Road, Ann Arbor, MI 48109, USA
}

Received 23 August 1999; accepted in revised form 30 October 1999

\begin{abstract}
In order to improve engineering product designs and reduce the number of problems that occur during a new product launch. firms have focused on integrating downstream product development processes into the design phases. Unfortunately, this resource integration to solve problems has been less common in the back-end of product development, particularly for complex products involving many components such as an automotive body. Here. manufacturing firms use sequential validation procedures first to approve components, then subassemblies, and finally the end product. One trend has been to tighten component tolerances in efforts to avoid or minimize downstream assembly problems. These stricter component requirements, however, often result in timing delays and cost overruns due to unnecessary rework of components. For complex-assemblies. the use of "flexible criteria" and an approach called "functional build" can significantly reduce validation time and costs yet still meet end product quality objectives. This paper examines this functional build approach to manufacturing validation and demonstrates its effectiveness with an automotive case example.
\end{abstract}

Key Words: manufacturing validation, process capability, automotive bodies, integrated product and process development, metal stamping, tolerances.

\section{Introduction}

As product life cycles shorten, manufacturers place a greater emphasis on new product development. These efforts have lead to reductions in costs and lead time. A principal driver of these improvements has been more effective integration of development resources into the product and process design phase through practices such as concurrent engineering, design for manufacturability, and partnership sourcing [1-3]. This resource integration, however, has been far less common in the back-end of product development. During this phase, manufacturers often attempt to execute a sequential validation process whereby they first try to "buyoff" or approve all individual components. Once components are approved, manufacturers then validate sub-assembly and final assembly processes. This sequential approach subscribes to the basic paradigm that final product quality is maximized if the mean of each individual component dimension is produced to its target specification with minimal variation.

In practice, few manufacturers execute a sequential process validation approach where final assembly validation starts on schedule with all component quality requirements met. Instead, manufacturers either start assembly validation with non-approved components or delay the start of validation as they wait for suppliers to resolve non-conforming is-

'Author to whom correspondence should be addressed sues or incorporate late engineering changes. Costs associated with these delays often follow a Pareto principle where reworking $10-20 \%$ of component dimensions may account for $80-90 \%$ of the total late time. The effects of these delays often become compounded during final assembly validation as manufacturers discover new assembly problems, resulting in additional rework of components. In addition, some of the non-conforming issues worked on during component validation are later found to have minimal impact on the final assembly, questioning the importance of meeting the original criteria. Although better integration of resources into the design phase can significantly reduce the number of problems in the back-end of product development. problems still arise. Thus, the effectiveness of identifying and resolving manufacturing validation problems becomes critical to the overall costs and time to launch a new product.

The effectiveness of manufacturing validation often depends on the ability to develop criteria and procedures that separate real problems from those non-conformities that do not affect the end product. At times, manufacturers of complex products over-focus their validation efforts on meeting component requirements to the detriment of validating the final product. They rework component features that slightly deviate from design intent only to discover more significant problems when they assemble the components. Unfortunately, if component suppliers are not meeting all the original quality requirements, they become easy targets to blame for product launch problems. As a result, suppliers continue to 
rework their components even when some of the non-conformities have a low likelihood of affecting the final product.

In efforts to minimize problems during manufacturing validation of the end product. companies often tighten component requirements in attempts to legislate better quality. They assign these stricter requirements on design prints without demonstrating that their processes have the ability to physically meet them. In contrast to this approach, this paper will show that for many complex product assemblies, manufacturers may substantially improve the effectiveness of the total manufacturing validation process through loosening rather than tightening component requirements. Critical to this strategy is the integration of product and process design resources forward into the manufacturing validation phase of new product development. One approach to executing this strategy is through a process known as functional build. Under functional build. component suppliers are required to first get their products within design windows. but not necessarily achieve $100 \%$ compliance for all part characteristics. Manufacturers then use downstream assembly validation processes to determine which component non-conformities must be reworked to build an acceptable final product. This strategy will be demonstrated using several case studies of the development of automotive bodies.

\section{Problem Identification and Resolution Processes}

One guarantee in manufacturing validation is that problems will arise. Parts and processes will have design errors: part dimensions will be produced out-of-specification; assembly processes will be unable to assemble certain components. These problems often relate to a lack of understanding of component-assembly build relationships and the difficulties in assigning a product specification [4]. Product specifications usually consist of a target value (desired measurement) and a tolerance. The tolerance represents the allowable deviation from the target in which the designer believes the product may vary and still yield an acceptable assembly. Two common problems with assigning product specifications are incompleteness and over-specification [3]. Incompleteness is the failure to identify all critical features; over-specification occurs when manufacturers try to minimize their downstream assembly problems by requiring that their suppliers (in-house or external) meet unrealistically narrow tolerances. Unfortunately, the real effect of not meeting a component target or tolerance may remain unknown until assembly process validation.

To minimize assembly validation problems, most of the product development research describes methods used to prevent problems from occurring in the first place. The principal strategy proposed to minimize downstream problems is integrated product development. Many researchers have noted the benefits of integrated product development on quality, timing and cost [5,6]. For instance, Ettlie [7] demon- strates the relationship between integrated product development and product quality improvements, both in terms of specification conformance and customer satisfaction. However, no matter how well designed a product is, problems will occur during a product launch. Given this reality, companies must effectively identify and resolve problems, without expensive process rework. Problem identification and technological learning, like problem avoidance, also has been the focus of product development research.

Problem identification and resolution is linked to a firm's ability to acquire technological knowledge during a production ramp-up. Bohn [8] develops an eight-stage framework for measuring and managing technological knowledge of manufacturing processes and notes that noise in manufacturing processes may reduce the rate of technological learning, thus prolonging the product development and launch stages. In another paper, Jaikumar and Bohn [9] relate the stages of knowledge to a product launch. They discuss how the effectiveness of pilot lines may be reduced when knowledge about the component parts and processes used to assemble a product is low. For example, if a firm attempts to resolve a production problem by tightening tolerances on a component about which knowledge is relatively low, interactions among people. machines and other components that were previously unimportant may become significant and cause problems greater than the original one.

To acquire technological knowledge during manufacturing validation, firms typically use either learning by experimentation or in-process learning. Upton and Kim [10] note that many firms become locked into one of these two methods of learning. This limits their technological knowledge and ability to solve production problems. Ward et al. [11] illustrate how Toyota attempts to avoid locking itself into one mode of learning by delaying the finalization of specifications, in order to incorporate technological lessons learned during prototyping into the original design whenever possible. Bhattacharya et al. [4] also examines the benefits of delaying final customer specifications through a flexible product definition process. Most of the models on delaying final specification decisions focus primarily on the front-end of product development - the design stage. A less developed aspect has been in developing executable, flexible strategies for the back-end of product development.

\section{Process Validation Criteria: $C_{p}$ and $C_{p k}$}

The most common evaluation criteria used by industry to identify problems in components and assemblies during manufacturing validation are the process capability indices, $C_{p}$ and $C_{p k}[12]$. These indices measure the ability of a process to produce parts within the specified tolerance width. This tolerance width (difference between upper and lower specifications) represents the allowable variation from a target value by design. The $C_{p}$ index is a ratio between the tolerance width and the total range of process variation. The $C_{p k}$ 
index differs from $C_{p}$ because it also considers the deviation of the mean from the target (nominal) specification. The $C_{p k}$ index becomes increasingly smaller than $C_{l}$ the further the mean deviates from nominal.

Manufacturers typically assign performance standards for $C_{p}$ and $C_{p k}$ that reflect desired quality levels in terms of defects. For example. achieving a $C_{p k}>1.67$ (hence $C_{p} \geq 1.67$ ) implies a potential to produce less than 1 defect per million. By examining both the $C_{p}$, and $C_{p k}$ index, manufacturers may determine if their problems relate to excess variation (fail $C_{p}$ ) or large mean deviations (pass $C_{p}$, fail $C_{p k}$ ).

$C_{p}$ and $C_{p k}$ indices have become widely accepted in many industries because they provide objective criteria to evaluate the conformance of components to their design requirements. Another appeal of these indices is their simplicity. Since their values are relative to tolerances. their interpretation is the same for any measured part characteristic. By using $C_{p}$ and $C_{p k}$, manufacturers may assign one generic quality standard for all part measurement characteristics.

Many researchers have commented on the potential problems of using process capability indices. Their concerns typically relate to the underlying statistical assumptions such as normality and sample size in calculating these indices [13] as well as the tendency to relate $C_{p}$ and $C_{p k}$ to arbitrary loss functions, for which they were not intended [14]. In addition to these statistical concerns. process capability indices also have limitations in identifying quality problems during manufacturing validation.

The effectiveness of using the $C_{p k}$ index for manufacturing validation often depends on the ability to adjust mean dimensions. Consider the situation presented in Figure 1 where a part characteristic has low variation (passes $C_{p}$ ) but fails $C_{p k}$ due to a mean deviation. For processes such as machining. manufacturers may inexpensively shift this mean to nominal by adjusting cutting tools. For example, in a vertical machining operation, operators may adjust the positioning of a cutting tool up or down to shift a part dimension to its target specification.

For many processes, however, simple adjustment factors like these do not exist. In the case of dies or molds, manufacturers usually must physically reshape the tools to adjust a mean dimension. Furthermore, rework for these processes often is inexact. In the case of stamping dies, metal will

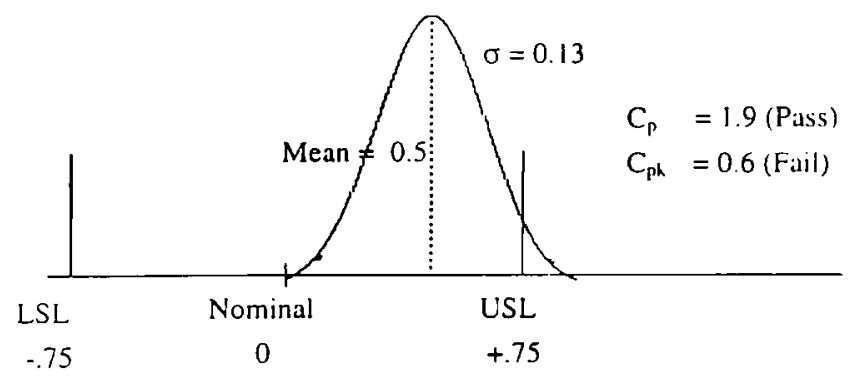

Figure 1. Example of a dimension with stable variation but off target. spring back once the component is released from the die. For other part characteristics, manufacturers have difficulty predicting the metal flow during forming operations. These difficulties are compounded by interrelationships between material properties, dies and part designs. In some cases, reworking a process to shift one part characteristic closer to target may adversely affect another.

The principal concerns with these difficult-to-adjust processes during manufacturing validation are excessive rework costs and longer lead-times. In the case of automotive stamped parts. $20 \%$ of the cost of the manufacturing dies may be attributed to rework [15]. When considering all the components within a vehicle, the total rework cost may reach $\$ 20$ million. Even with this extensive rework, automotive body manufacturers routinely begin assembly validation with component mean dimensions significantly deviating from target specifications.

Cost and lead-time concerns resulting from reworking components to meet $C_{p k}$ requirements become particularly disconcerting. if a manufacture" discovers during final assembly validation that achieving $C_{p k}$ requirements for certain characteristics was unnecessary. As mentioned previously, product designers will over-specify component requirements to reduce the risk of downstream assembly problems. The flip side of this approach is that manufacturers will rework components during manufacturing validation to meet unnecessarily tight tolerances.

One effect of assigning unrealistic tolerances is that the $\mathrm{fi}_{\mathrm{i}}$ nal specifications for component quality characteristics become negotiated during manufacturing validation. As launch dates near, manufacturers will negotiate new, attainable tolerances with designers so that all component dimensions meet a quality standard such as $C_{p k}>1.33$. This tolerance negotiation is not necessarily a system flaw but a manufacturing reality. Unfortunately, manufacturers using process capability indices such as $C_{p}$ and $C_{p k}$ often view tolerance modifications as a last resort rather than a normal activity within the manufacturing validation process. They continue to rework processes until they run out of time and then they ask for tolerance adjustments. The fact that they ultimately produce end products that meet customer requirements with some individual component dimensions not meeting their original specifications indicates a potential to avoid unnecessary rework. If a non-conforming component feature does not affect the quality or function of the end product, a tolerance adjustment to the part print costs significantly less than physically reworking or re-designing the component process.

\section{Case Example: Evaluating the Effectiveness of $C_{p k}$}

To produce an automotive body, manufacturers assemble 150-200 stamped components. One challenge with stamping these components is trying to simultaneously produce ev- 


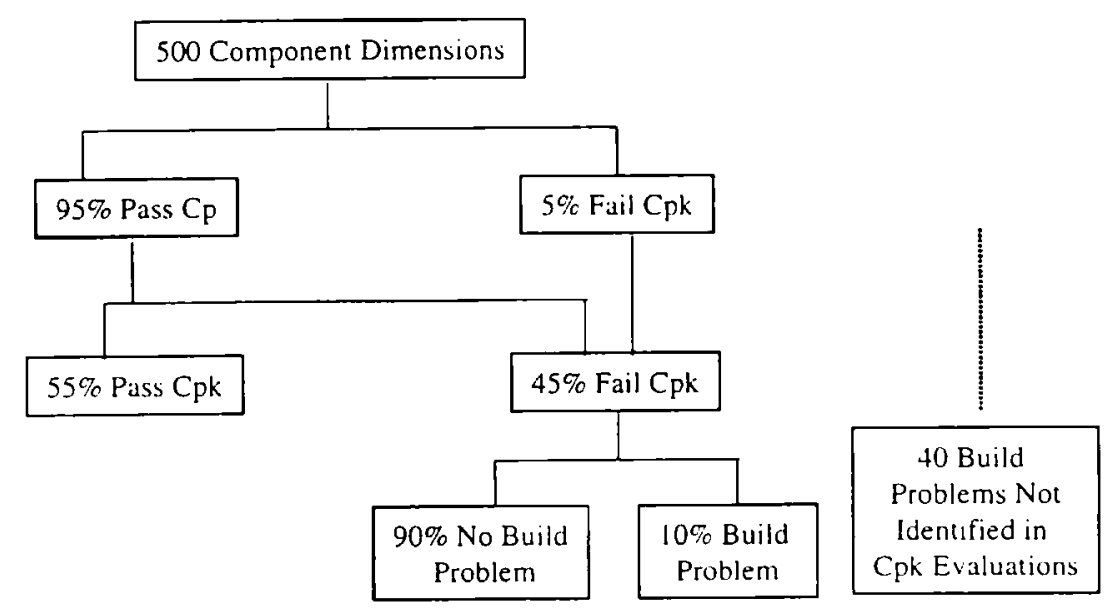

Figure 2. Relationship between assembly-build problems and $C_{p k}$ conformance.

ery part dimension mean at its target. Ultimately, body manufacturers must address the effects of off-target mean deviations on assemblies particularly if the variation of the component dimension is stable and meets $C_{p}$, standards. Figure 2 summarizes $C_{p}$ and $C_{p k}$ conformance and their relationship to assembly problems for 500 dimensions on 30 body side components near the start of manufacturing validation. Although this manufacturer is able to meet the variation requirements. $C_{p}>1.33$, for $95 \%$ of the part dimensions relatively quickly, they have numerous mean dimensions off-target $(45 \%)$ resulting in unacceptable $C_{p k}$ values.

Rather than reworking all of these component dimensions until achieving $C_{p k}$, this manufacturer evaluated the effect of each component mean deviation on the assembly process. Figure 2 indicates that of the dimensions failing $C_{p k}$ ( 225 out of 500 ), only $10 \%$ related to actual assembly build problems. By evaluating these component features relative to mating parts and not solely based on $C_{p k}$ standards, this manufacturer avoided unnecessary rework for $90 \%$ of the dimensions that failed their initial requirements. Interestingly, this manufacturer did identify 40 build problems with these components that did not surface using $C_{p k}$ evaluations. These build problems related to design errors (dimensions met $C_{p k}$ but did not assemble properly) and deviations in non-measured areas of the part. For complex body panels, manufacturers cannot realistically measure every possible point on the part surface. As a result, some problems do not arise until manufacturers physically assemble components.

\section{Replacing $C_{p k}$ with Flexible Criteria}

Many companies use $C_{p}$ and $C_{p k}$ criteria to approve components for regular production. These criteria essentially require variation conformance for all component part characteristics. In prior sections, concerns were raised about the use of these indices, particularly for hierarchical assemblies involving numerous complex components. The remainder of this paper discusses the development of al- ternative validation criteria for multi-component assemblies.

Specifications for the final assembled product are critical because these typically have direct relationships with customer satisfaction. In the case of an automotive body, customers expect a parallel gap between exterior panels such as the hood and fender. If the gaps have severe out-of-parallel appearances, customers may perceive a poorly manufactured product and choose not to buy it. For end product requirements, the use of $C_{p k}$ provides an effective tool to insure product conformance assuming a reliable system exists to measure the feature and the tolerances reflect customer expectations. For components within an assembly, however, determining appropriate validation criteria is less clear. For instance, external customers really do not care if component characteristics are within their original tolerances (pass $C_{p k}$ ) provided the final product is acceptable.

Although external customers may not care, original equipment manufacturers (OEMs) often require that component suppliers meet $C_{p k}$ performance standards for all designated product characteristics. Their principal argument for strict $C_{p k}$ compliance is to reduce the risks of problems during final assembly manufacturing validation. Unfortunately, strict adherence to $C_{p k}$ quality requirements for components often creates another set of problems in terms of high rework costs and timing delays if a supplier has difficulty meeting the standards based on the original tolerances.

Thus, the following recurring situation occurs when suppliers are late delivering products. Suppliers are late because they are unable to meet $C_{p k}$ objectives for features that they believe have unnecessarily tight tolerances. Assemblers, even if they agree that the tolerances are too stringent, are reluctant to approve components not meeting all $C_{p k}$ objectives. They are concerned that if an assembly problem does occur, they will be blamed for accepting the non-conforming components. The safest position for assemblers is to demand that suppliers meet all original design criteria. Ultimately, however, the decision process changes because of time constraints. As the start of production nears, assemblers will take 
non-conforming components and work closely with suppliers to only change what is necessary to produce an acceptable final product. Ultimately time pressures force value-added rework decisions.

This low assembly risk approach involving strict $C_{p k}$ compliance often becomes sub-optimal when viewing the backend of product development as a total system. Manufacturers recognize that component suppliers often will not meet all their $C_{p k}$ requirements using the original design tolerances. They also know from experience that certain component features failing $C_{p k}$ will not affect the final product. Thus. if suppliers rework components based strictly on $C_{p k}$ criteria, they will perform unnecessary rework that will add cost and time to the overall system validation. Assemblers, however, recognize that they are essentially absolved of responsibility for most final product quality problems as long as individual components are not approved, making them risk-adverse to early tolerance adjustments. At the core of this conflict is the intent to execute sequential validation. By utilizing flexible criteria to allow more concurrent component and assembly validation. manufacturers can reduce total system costs and lead-time.

One approach to adding flexibility in component validation criteria is to separate mean and variation conformance rather than combine them in $C_{p k}$. For instance. manufacturers would use $C_{p}$ criteria to insure that the process variation is acceptable, but not necessarily require that all mean deviations be centered at the target value. For example, a manufacturer could require a $C_{p}>1.33$ and a mean within the tolerance limits (as opposed to closely near the target value) to start assembly validation. The flexibility here is that mean dimensions may moderately deviate from the original target specification and some parts may be produced outside the original tolerance limits. Under this approach, manufacturers could begin assembly validation sooner rather than trying to rework a stable process to improve mean conformance. This approach recognizes that some component features that pass $C_{p}$ but fail $C_{p k}$ may later be reworked based on the assembly build, but other features may only require a part print tolerance adjustment.

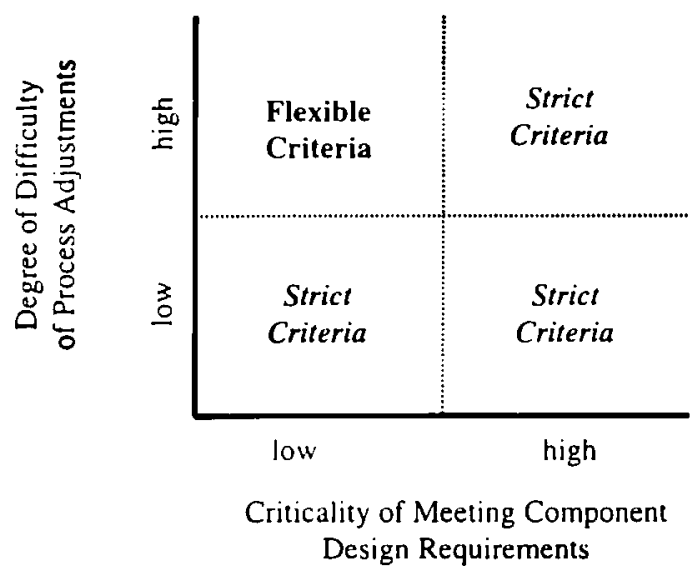

Figure 3. Flexible versus strict criteria.
Under this approach, components are nearly simultaneously approved with their assemblies. This approach represents a tremendous paradigm shift from sequential validation. Interestingly, timing pressures in sequential validation typically lead to simultaneous component and assembly approval anyway as the deadline approaches. The advantage with this approach is that by using flexible, looser criteria for components. manufacturers may avoid many of the nonvalue added rework decisions trying to meet $C_{p k}$ criteria than when used as a last resort

The effectiveness of flexible criteria systems is not universal to all products. Their advantages clearly relate to certain process and assembly characteristics. Two of these factors are the difficulty in making component process adjustments (i.e., known mean shifts) and the criticality of meeting the original component design requirements. Criticality defined here relates to the robustness of the assembly process to component deviations, the relative ease of changing mating components. and the ability to make downstream adjustments in the assembly process. For example, many downstream processes can compensate for a non-conforming mean of a component by adjusting an assembly tool provided that the variation is stable.

Figure 3 compares the ease of component process adjustment and dimensional criticality with the use of either flexible or strict criteria. Again, strict criteria imply that component approval requires that all characteristics meet their quality standards using the original tolerances. Utilizing flexible criteria entails specifying looser component criteria and then near simultaneous approval of components and final assemblies based on the quality of the build and not necessarily conformance of component features to $C_{p k}$.

If process adjustments are relatively simple (i.e., low cost), then manufacturers should utilize strict criteria. There is no reason to increase assembly risk if manufacturers may easily achieve their component requirements. If the criticality of meeting component requirements is high, manufacturers also should maintain strict criteria. The assumption here is that non-conforming component features will ultimately require rework until they comply with design requirements, so little value exists in delaying rework until after components are evaluated in their assemblies. The use of flexible criteria appears most promising if the component process adjustment difficulty is high and the criticality of meeting the original specifications is relatively low. Although this represents only one of the four quadrants, it applies to many complex assemblies where the back-end of product development presents the greatest challenge. The next section discusses how automotive firms apply flexible criteria to manufacturing validation of the body using a functional build strategy.

\section{Functional Build: A New Paradigm}

Rather than sequential validation, several automotive manufacturers use functional build strategies for manufac- 


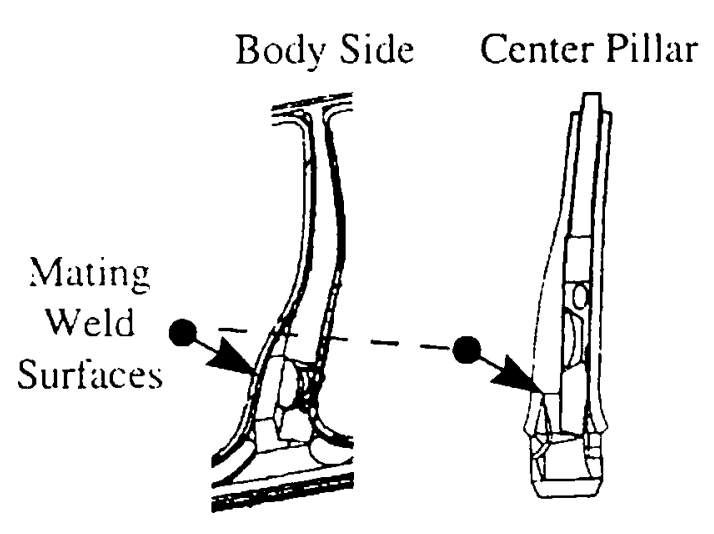

SIDE VIEW

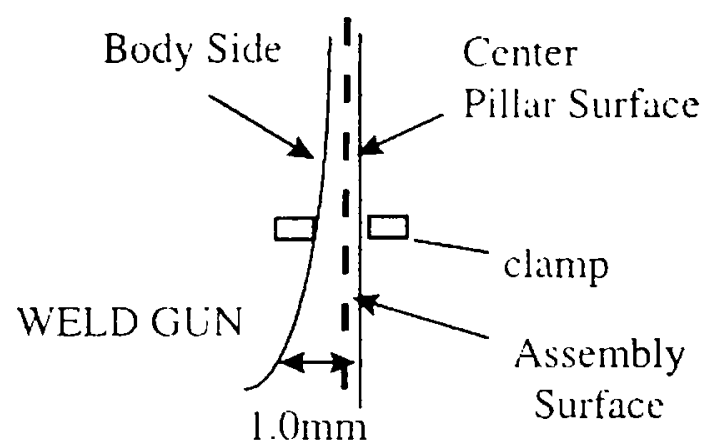

Figure 4. Parallel assembly of a non-rigid mating surface to a rigid reinforcement.

turing validation of stamped body components. Under functional build, rather than validating components solely to their part print specifications, manufacturers also evaluate components relative to their mating parts and subsequent assembly processes. Manufacturers treat original design specifications as goals rather than absolute requirements. For example. if a manufacturer experiences difficulty meeting a particular component requirement. they may be able to resolve the problem in a downstream assembly process or change another related, mating component more expediently. By analyzing components in their subsequent assemblies, manufacturers may find that certain original requirements are not critical to the final product build. Here, a modification to the design print is less expensive than physically changing already-constructed manufacturing tooling such as a metal stamping die.

Functional-build type practices for automotive body validation have existed for several years. The principal evaluation tool, or screw-body process, may be traced to the carly 1970 s to a process known as "screw and scribe." Here. manufacturers would screw mating components together to check for assembly interference. Toyota iterated on this process and began using it as an evaluation tool for component rework decisions. Today, several companies including General Motors and Chrysler [16] use functional-build type strategies.

Under functional build, manufacturers use the validation process to dynamically set final component design specifications in accordance with the capabilities of the constructed processes. Suppose a dimension has a $C_{p k}$ of 0.52 (tolerance $= \pm 0.7 \mathrm{~mm}$, mean $=0.5 \mathrm{~mm}$. and $C_{p}=1.83 \mathrm{~mm}$ ). If this dimension results in an acceptable assembly, they would shift the target $0.5 \mathrm{~mm}$ and then laterally adjust the tolerance from -0.2 to 1.2 instead of reworking the mean. (Note: the total tolerance width would remain $1.4 \mathrm{~mm}$.)

In delaying final product specifications during manufacturing validation, one must recognize the difference between "tweaking" specifications and major design changes. In the above example, the overall tolerance width did not change, and the target only shifted $0.5 \mathrm{~mm}$ (which is relatively minor for automotive body assembly of non-rigid sheet metal components). Automotive companies using functional build rarely incorporate major design changes such as shifting a target value $3 \mathrm{~mm}$. The principal issue here is that statistical criteria such as $C_{p}$ or $C_{p k}$ should aid in, but not provide the sole determination of acceptable component quality. Ultimately. a manufacturer must make some experienced-based decisions irrespective of $C_{p k}$.

When functional build is used. manufacturers may realize substantial cost savings over a traditional process and product development life cycle. These savings result from eliminating unnecessary process rework during the manufacturing validation phase. Under functional build, rework decisions focus on meeting final vehicle objectives and not necessarily on conformance to all original component specifications.

To execute a functional build approach, automotive body manufacturers assemble components into prototype car bodies or "screw bodies." The individual components used to construct these screw bodies are stamped using their regular production dies. Manufacturers evaluate these components in relation to their mating automotive body parts. Components do not necessarily have to strictly comply with their original design specifications. If a part assembles into an acceptable car body, it is not modified regardless of whether it meets a $C_{p k}$ requirement.

To illustrate why the functional build approach works, Figure 4 considers the mating of the center pillar reinforcement and the body side panel. The center pillar reinforcement is a thicker. structural component and thus will have greater influence on the final assembly. Even though this body side panel dimension is $1 \mathrm{~mm}$ outboard from the design target, the center pillar is at nominal, thus the overall assembly shifts toward nominal. This shift occurs because the mating surfaces are in parallel. Thus, the less rigid body side panel conforms to the rigid inner structure [17].

Under a traditional build-to-nominal approach, a manufacturer would likely rework the body side panel because the outboard stamping condition would cause this part to fail its $C_{p k}$ requirements. In contrast, a functional build manufacturer would assemble these two components and then deter- 
mine rework decisions based on the resultant assembly and not necessarily on $C_{p k}$ compliance. In some cases, a resultant assembly might still deviate from nominal, but it may be easier and less costly to adjust an assembly process tooling locator to shift the assembly mean rather than physically alter the body-side stamping die.

When making a change under a functional build approach, manufacturers scarch for the least costly alternative without sacrificing end-product quality. For example, if the quality of the body is unacceptable because an overall dimension of several parts in a subassembly is too long, only one part may need rework. In many cases, manufacturers choose the least expensive process for rework even if it produces a part with dimensions inside specification limits. For example, a dimension with a measurement of $0.5 \mathrm{~mm}$ out-of-tolerance could mate with a dimension at its nominal. In some cases, altering the dimension at nominal is less expensive than reworking the out-of-specification condition. The objective is to produce an acceptable final assembly. This solution might differ for a manufacturer using a traditional, sequential validation approach where each part is evaluated independently against its design print specifications. Here, a manufacturer might change the more expensive process or possibly both processes.

The functional build approach resembles robust engineering methods [18] as manufacturers seek to redefine component tolerances in which the assembly is insensitive to component variations. However, two important distinctions should be made between functional build and most robust design methodologies. The first distinction relates to tolerance expansion versus nominal adjustments. Functional build typically involves redefining nominal specifications while maintaining design tolerance widths or allowable component variations. In other words, functional build suggests that a mean deviation from the original nominal specification during manufacturing validation may result in zero loss if this mean is maintained in regular production. However, once this new nominal is established, functional build manufacturers typically try to maintain the allowable variation specified with the original tolerance widths. In contrast, robust design methods usually involve expanding component tolerance widths provided the additional component variation does not adversely affect the assembly. A second distinc- tion with functional build is that it is rarely based on planned experimentation. The principal reasons that manufacturers utilize functional build relate to their inability to produce component dimensions at nominal and the complex correlation structure that exists for multiple dimensions on the same component. These two factors significantly hinder the ability to construct meaningful experiments that independently assess the impact of different component dimensions on a resultant assembly. If experimentation is used, it typically involves adjusting assembly parameters to determine if component rework may be avoided.

\section{Functional Build Case Studies}

To highlight the potential effects of applying flexible component criteria in the back-end of product development, we examine three automotive body launches. Table I summarizes key differences and similarities between launches.

Table 2 compares the validation performance for each launch. In the first case study, the manufacturer has strict $C_{p k}$ requirements for all part dimensions. As such, they submit more components late to assembly validation and not surprisingly have difficulty getting parts approved for production. One reason is that many build problems are not identified until assembly validation. By over-focusing on meeting component requirements, this manufacturer limits their capability for early detection of those assembly build concerns that affect external customer perceptions.

Case Study II also involved strict criteria for component dimensions, but this manufacturer places a greater emphasis on schedule conformance. They begin assembly validation on schedule even if component dimensions are not in compliance. Unfortunately, they use assembly validation primarily to identify new build problems and not necessarily to evaluate if non-conforming component features affect the build. As a result, they continue to rework components trying to meet original specification requirements in addition to incorporating engineering changes to correct assembly build concerns. In efforts to minimize the risk of assembly problems, this manufacturer also assigns tighter tolerances on components than the other manufacturers. Their efforts to achieve tighter tolerances, however, result in higher component re-

Table 1. Comparison of validation criteria.

\begin{tabular}{|c|c|c|c|}
\hline Criteria & Case Study I & Case Study II & Case Study III \\
\hline Car size & Small car & Small car & Small car \\
\hline Location of product launch & North America & Europe & South America \\
\hline $\begin{array}{l}\text { \# of new body components } \\
\text { evaluated }\end{array}$ & 104 & 280 & 128 \\
\hline $\begin{array}{l}\text { Body component validation } \\
\text { time (weeks) }\end{array}$ & -50 weeks & $\sim 50$ weeks & -50 weeks \\
\hline $\begin{array}{l}\text { Component validation criteria } \\
\text { (and priority) }\end{array}$ & $\begin{array}{l}\text { 1. } C_{p k}>1.67 \\
\text { 2. Meet schedule }\end{array}$ & $\begin{array}{l}\text { 1. Meet schedule } \\
\text { 2. Sample of one in tolerance }\end{array}$ & $\begin{array}{l}\text { 1. Meet schedule } \\
\text { 2. Produce acceptable final product }\end{array}$ \\
\hline
\end{tabular}


Table 2. Comparison of component criteria and approval rates.

\begin{tabular}{|c|c|c|c|c|}
\hline $\begin{array}{l}\text { Case } \\
\text { Study }\end{array}$ & $\begin{array}{c}\text { Component Requirements } \\
\text { to Start Assembly } \\
\text { Validation }\end{array}$ & $\begin{array}{l}\% \text { Dimensions within } \\
\text { Specification at Start } \\
\text { of Mfg. Validation }\end{array}$ & $\begin{array}{c}\% \text { Components } \\
\text { Submitted on Time for } \\
\text { Mig. Validation }\end{array}$ & $\begin{array}{l}\% \text { Components } \\
\text { Approved (by } 8 \text { weeks } \\
\text { before production start }\end{array}$ \\
\hline 1 & $\begin{array}{l}\text { Strict } C_{\rho k} \text { criteria for all } \\
\text { component dimensions }\end{array}$ & $82 \%$ & $25 \%$ & $75 \%$ \\
\hline II & $\begin{array}{l}\text { Strict criteria for all compo- } \\
\text { nent measurements in } \\
\text { specification }\end{array}$ & $76 \%$ * & $90 \%$ & $45 \%$ \\
\hline III & $\begin{array}{l}\text { Flexible criteria: require } 80 \% \\
\text { dimensions in specification }\end{array}$ & $85 \%$ & $90 \%$ & $95 \%$ \\
\hline
\end{tabular}

- Note: the tolerances used to approve these components are tighter than at the other case studies.

work costs and longer lead-times to get components approved.

The most interesting results occur in Case Study III. This manufacturer has the loosest component requirements but actually approves components at a faster rate. They have near simultaneous approval of components and assemblies, rather than the traditional sequential approach. Their goal is to first produce parts with stable variation and mean dimensions within a design window $(80 \%$ of part dimensions within specification). They then use downstream manufacturing validation processes to determine which component dimensions require rework.

The key for this manufacturer is the close relationship between evaluators of components and assemblies. Their assembly validation team recognizes that meeting all component requirements is not necessarily critical to the build. and as a result, more willingly accepts non-conforming component dimensions. Their functional build stralegy does not presume that all component deviations are acceptable. They rework some component mean deviations, but they also compensate for component mean deviations by adjusting assembly tooling or other mating components. Regardless of the solution. functional build manufacturers are focused on the final product objectives rather than trying to optimize individual component performance.

A hidden key to the success in Case Study III is that one manager is responsible for both stamped component and $\mathrm{fi}_{\mathrm{i}}$ nal assembly quality. From his total system perspective, he looks for the least expensive, rational quality decision to every problem. He is not concerned whether this involves reworking the component process or making an adjustment in downstream assembly processes.

\section{Conclusions}

One result of rising expectations for improved time-tomarket and final product launch quality has been to require that suppliers meet strict component criteria with evertighter manufacturing tolerances. Unfortunately, several manufacturers tighten component tolerances without rigorously validating that the revised tolerances will actually im- prove assemblies. Or. they do not consider the additiona supplier burdens resulting from assigning unrealistically tight tolerances. These manufacturers simply want to "draw : line in the sand" and tell suppliers that their components mus conform to all requirements.

For components within a complex assembly, this research suggests that loosening component criteria may actually lear to a more efficient manufacturing validation process. Using : functional build approach, manufacturers no longer trea original tolerances as sacred. thus allowing them to eliminats unnecessary rework. By viewing validation as a total system functional build manufacturers search for the best busines: decision to produce an acceptable end product. This decisior might entail reworking a non-conforming component, a mat ing component, or making an adjustment to a downstream as sembly process. As with the front-end of product develop ment, improving manufacturing validation ultimately depends on better integration of component suppliers and fi nal manufacturers toward solving those problems that truly affect the final customer.

\section{References}

1. Clark, K.B. and T. Fujimoto 1991. Product Developmen Performance-Strategy. Organization. and Management in the World Auto Industry. Boston. MA: Harvard Business Schoo Press.

2. Kamath. R.R. and J.K. Liker 1994. "A Second Look at Japa nese Product Development," Harvard Business Review, Nov. Dec.

3. Karlsson. C.. R. Nellore and K. Soderquist 1998. "Black Bo" Engineering: Redetining the Role of Product Specifications.' Journal of Product Innovation Management. Vol. 15. No. 6.pp 534-549.

4. Bhattacharya, S., V. Krishnan, and V. Mahajan 1998. "Man aging New Product Definition in Highly Dynamic Environ ments," Management Science, Vol. 44, No. 11. November, pp S50-S64.

5. Moffat, L.K. 1998. "Tools and Teams: Competing Models o Integrated Product Development Performance," Journal of En gineering Technology Management. Vol. 15, pp. 55-85.

6. Haddad. C. 1996. "Operationalizing the Concept of Concur rent Engineering: A Case Study from the U.S. Auto Industry.' 
IEEE Transactions on Engineering Management, Vol. 43, No. 2, May, pp. 124-132.

7. Ettlie. J.E. 1997. "Integrated Design and New Product Success." Journal of Operations Management, Vol. 15, pp. 33-55.

8. Bohn, R.E. 1994. "Measuring and Managing Technical Knowledge." Sloan Management Review. Fall 1994

9. Jaikumar. R. and R.E. Bohn 1992. "A Dynamic Approach to Operations Management: An Alternative to Static Optimization," International Journal of Production Economics, Vol. 27, pp. 265-282

10. Upton, D.M. and B. Kim 1998. "Alternative Methods of Learning and Process Improvement in Manufacturing." Journal of Operations Management, Vol. 16, pp. 1-20.

11. Ward, A., J.K. Liker, J.J. Cristiano, and D.K. Sobek 1995. "The Second Toyota Paradox: How Delaying Decisions Can Make Better Cars Faster," Sloan Management Review, Vol. 36. No. 3. Spring. pp. 43-61

12. Liggett, J.V. 1993. Dimensional Variation Management Handbook-A Guide for Quality. Design, and Manufacturing Engineers. Englewood Cliffs, NJ: Prentice Hall.

13. Rodriguez, R.N. 1992. "Recent Developments in Process Capability Indices," Journal of Quality Technology. Vol. 24, No. 4. October, pp. 176-187

14. Pearn. W.L.. S. Kotz and N.L. Johnson 1992. "Distributional and Inferential Properties of Process Capability Indices." Journal of Quality Technology, Vol. 24. No. 4. October, pp. 216-231.

15. Hammett. P.C.. W.M. Hancock and J.S. Baron 1995. "Producing a World Class Automotive Body." Engineered in Japan-Japanese Technology Management Practices. Edited by J.K. Liker. J.C. Campbell, and J.E. Ettlie, N.Y.: Oxford Universily Press.

16. Rosink, K.E., T. Reynolds and M. Moulton 1997. "The Process Assurance Body Build Systems Tooling Build/Plate Build. What Are the Benefits?" Society of Automotive Engineers Paper No. 982404.

17. Liu, S.C., S.J. Hu and T.C. Woo 1996. "Tolerance Analysis for Sheet Metal Assemblies," ASME Journal of Mechanical Design. Vol. 118, March, pp. 62-67.

18. Prasad, B. 1997. Concurrent Engineering Fundamentals-Volume II, Prentice Hall, pp. 98-110.

\section{Patrick C. Hammett}

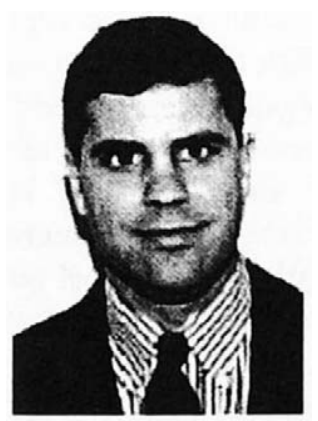

Pat Hammett, Ph.D., is an Assistant Research Scientist in the Manufacturing Systems Group of the Office for the Study of Automotive Transportation. He is involved in research developing and implementing world-class manufacturing. quality, and management practices in the production and development of the automotive body for Chrysler. Ford and General Motors. As part of the Body Systems Analysis Task Force of the Auto-Steel Partnership, a joint partnership consisting of General Motors, Ford, Chrysler, and twelve North American steel manufacturers, Pat conducts research to as- sist the North American stamping industry in achicving world class performance levels in automotive body development lead time and dimensional quality. Pat is a principal researcher and supervisor for several research projects to optimize the automotive body development process at General Motors Corporation. He is also Adjunct-Assistant Professor of Industrial and Operations Engineering, teaching a course on Total Quality Management for the College of Engineering for senior engineers and graduate students.

Pat has a Ph.D. in Industrial and Operations Engineering from the University of Michigan, a Master of Science in Engineering from the University of Michigan, and a Bachelor of Science in Engineering from Purdue University.

\section{Shannon Wahl}

Shannon Wahl is a student research assistant in the Manufacturing Systems Group at the Office for the Study of Automotive Transporation at the University of Michigan. As a research assistant, she has been involved in a variety of projects to optimize the automotive body-in-white development process, as well as projects dedicated to understanding and implementing world-class manufacturing practices. Shannon received her Bachelor of Science degree from the University of Michigan in Industrial and Operations Engineering and is currently pursuing her Master of Science degree in the same area of study.

\section{Jay S. Baron}

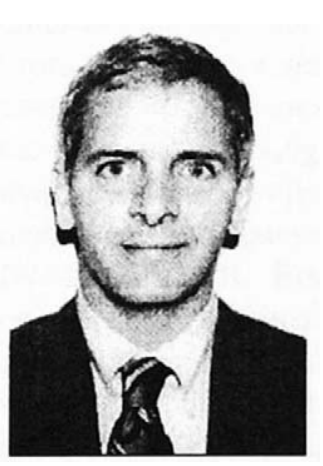

Jay is the Manager of Manufacturing Systems for the Office for the Study of Automotive Transportation. He holds a Ph.D. and Master's Degree in Industrial and Operations Engineering from the University of Michigan, and an MBA from Rensselaer Polytechnic Institute.

Dr. Baron has been researching techniques for achıeving process and dimensional control in sheet metal stamping and auto body assembly. As part of his doctoral research, he has developed new analytical methods and procedures to support the dimensional analysis and control of stamped metal assemblies.

Dr. Baron has also been researching evolving technologies in the auto industry. His interests are to conduct manufacturing analysis and planning for the automotive industry, concentrating on productivity, product quality, and system economics, and to assist in the development and application of new manufacturing technologies such as computer-assisted manufacturing, laser welding. hydro forming. sheet metal adhesives, and process control systems. Dr. Baron's primary interests are researching and improving product develop- 
ment and manufacturing process capability through effective design, development and implementation.

Prior to becoming a researcher at the University of Michigan, Dr. Baron worked for Volkswagen of America in Quality Assurance. He has also been a Staff Engineer and Project Manager at the Industrial Technology Institute in Ann Arbor, and Rensselaer Polytechnic Institute's Center for Manufac- turing Productivity in Troy, New York. While at these organizations, he managed consulting projects for over twenty different companies in applying new manufacturing technology. Several projects were concerned with manufacturing systems and economic modeling to evaluate the strategic and tactical deployment of technology. 